\section{1}

2

5

6

7

\section{Funding:}

\title{
Modulation of Pharyngeal Swallowing by Bolus Volume and Viscosity
}

\author{
Lara Ferris ${ }^{1}$, Sebastian Doeltgen ${ }^{2}$, Charles Cock $^{1,3}$, Nathalie Rommel ${ }^{4}$, Mistyka Schar ${ }^{1,5}$, Silvia \\ Carrión $^{6,7}$, Ingrid Scholten ${ }^{2}$, Taher Omari ${ }^{1}$ \\ 1 College of Medicine \& Public Health, Flinders University, Adelaide, Australia \\ 2 College of Nursing \& Health Sciences, Flinders University, Adelaide, Australia \\ 3 Department of Luminal Gastroenterology, Flinders Medical Centre, Adelaide, Australia \\ 4 Department of Neurosciences, Oto-rhino-laryngology Research Group, KU Leuven, Belgium \\ 5 Department of Speech Pathology \& Audiology, Flinders Medical Centre, Adelaide, Australia \\ 6 Gastrointestinal Physiology Laboratory, Department of Surgery, Hospital de Mataró, \\ Universitat Autònoma de Barcelona, Mataró, Spain \\ 7 Centro de Investigación Biomédica en Red de enfermedades hepáticas y digestivas (CIBERehd), \\ Instituto de Salud Carlos III, Barcelona, Spain
}

\section{Conflict of Interest:}

Author T Omari holds inventorship of the patent family that covers the analytical methods described. The Swallow Gateway web application is owned by Flinders University. All other authors report no conflict of interest.

Author T Omari holds a National Health \& Medical Research Council Senior Research Fellowship. The development of the swallowgateway.com website was supported by grants from the College of Medicine and Public Health, Flinders University. The other authors report no external funding for this manuscript. 


\section{Abstract}

Background: Oro-pharyngeal swallowing involves complex neuromodulation to accommodate changing bolus characteristics. The pressure events during deglutitive pharyngeal reconfiguration and bolus flow can be assessed quantitatively using high-resolution pharyngeal manometry (HRPM) with impedance.

Methods: An 8 French solid-state unidirectional catheter (32 pressure sensors, 16 impedance segments) was used to acquire triplicate swallows of 3- to 20- mls across three viscosity levels using a Standardized Bolus Medium (SBMkit) product (Trisco Pty Ltd, Australia). An online platform www.swallowgateway.com (Flinders University, South Australia) was used to semiautomate swallow analysis.

Results: Fifty healthy adults (29 female, 21 male; mean age 46 years; age range 19-78yrs old) were studied. Hypopharyngeal intrabolus pressure, upper esophageal sphincter (UES) maximum admittance, UES relaxation pressure and UES relaxation time revealed the most significant modulation effects to bolus volume and viscosity. Pharyngeal contractility and UES post swallow pressures elevated as bolus volumes increased. Bolus viscosity augmented UES preopening pressure only.

43 Conclusion: Describing swallow modulatory effects with quantitative methods in line with a 44 core outcome set of metrics, and a unified analysis system for broad reference contributes to 45 diagnostic frameworks for oropharyngeal dysphagia.

46 New and Noteworthy: The neuromodulation of the healthy oropharyngeal swallow response

47 was described in relation to bolus volume and viscosity challenges, using intraluminal pressure

48 and impedance topography methods. Among a wide range of physiological measures, those

49 indicative of distension pressure, luminal opening and flow timing were most significantly altered

50 by bolus condition, and therefore considered potential markers of swallow neuromodulation. The

51 study methods and associated findings inform a diagnostic framework for swallow assessment

52 in patients with oropharyngeal dysphagia. 


\section{Introduction}

55 The oro-pharyngeal swallow response requires complex neuro-regulation $(10,13,19,29,32$,

$5641,46,58)$. During volitional swallowing, bolus characteristics such as volume, taste, viscosity

57 and temperature are detected and relayed to the sensory cortex, and brainstem (19). These

58 sensory inputs enable adaptation of the swallow system for optimal bolus transfer from the oral

59 cavity to the esophagus.

60 The pressure events associated with the swallowing motor response can be recorded using

61 high-resolution pharyngeal manometry $(\operatorname{HRPM})(15,17,22,30,33,49,51,52,56)$ and bolus

62 flow events can be assessed when HRPM is integrated with impedance measurement (4, 5, 9,

$6314,25,26,37,42,54-56)$. Using this combined technique with automated analysis methods, a

64 rich, objective dataset of pressure and flow measurements can be acquired and used to detect

65 the swallow motor response in relation to bolus characteristics $(6,26,31,36,56,57)$. Most

66 recently, a core outcome set of parameters and protocols for HRPM with impedance

67 assessment has been suggested (39), providing a standardized approach to recording and

68 reporting HRPM measurements.

69 Bolus texture modification and volume regulation are regularly implemented in dysphagia

70 management with the intention to slow bolus flow, enhance bolus control, and optimize swallow

71 initiation and airway protection $(28,50)$, however, until now, the respondent swallow mechanics

72 have not been comprehensively documented $(35,60)$. Additionally, in clinical practice, optimal

73 viscosity levels for oropharyngeal dysphagia (OPD) treatment in the individual patient need to

74 be ascertained more discriminately across dysphagia-causing etiologies (2). Age-related

75 changes to swallow physiology are well recognized, particularly in adults over 60 years of age

76 (7). Gender has less impact on pharyngeal and UES contractility $(3,33,56)$, with only small 
77 effects seen for longer pharyngeal pressure duration in females (3), and there is greater

78 pharyngeal pressure during cued effortful swallowing (33).

79 The effects of bolus volume $(8,13,14,17,21,33,53)$, and viscosity $(23,33,53,56)$, on

80 unimpaired swallowing biomechanics have previously been documented with high-resolution

81 manometry. This study characterized the oro-pharyngeal swallow response to a wider than

82 previously studied, range of bolus volumes and consistencies using HRPM with impedance. We

83 aimed to determine which, of a recently established suite of core outcome metrics (39) and set

84 of novel bio-mechanical measures were most influenced by bolus condition, accounting for age

85 and gender effects. We tested the following hypothesis: parameters indicative of distension and

86 flow-timing would be the most responsive and therefore could, in the future, function as

87 diagnostic markers to detect impaired swallow modulation in patients with dysphagia.

88 Method

\section{Study cohort}

90 This prospective study was approved by the Southern Adelaide Clinical Human Research Ethics

91 Committee (SAC HREC EC00188). Healthy adults were enrolled between the ages of $18-80$

92 years unless they met the following exclusion criteria: previous abdominal or head \& neck

93 surgery; subject reported swallowing difficulties or symptoms of heartburn or regurgitation;

94 uncontrolled diabetes; blood pressure abnormalities; pregnancy; allergy to local anesthesia; and

95 medication affecting gastrointestinal motility. Any daily medications were assessed by the study

96 doctor (author CC) before enrolment. Dysphagia screening was conducted and produced

97 normal scores from the DAKKAK score (12) and Sydney Swallowing Questionnaire (62). All

98 manometry investigations were performed in the Gastroenterology \& Hepatology Department at

99 Flinders Medical Centre. In compliance with ethical requirements each participant was provided 
with refreshments on completion of the protocol, observed for 30 minutes and then contacted 24

101 hours following participation.

\section{High-resolution pharyngeal manometry with impedance}

103 An 8 French solid-state unidirectional high-resolution manometry catheter (32 pressure sensors

104 at 1cm, 16, $2 \mathrm{~cm}$ length impedance segments, Unisensor/Laborie, Attikon, Switzerland) was

105 used for data collection. Inbuilt catheter sensors detected pressures along the swallowing tract

106 from velopharynx to proximal esophagus. Adjacent impedance electrode segments

107 simultaneously detected bolus contact. Following data acquisition, each de-identified pressure-

108 impedance file was exported as an ASCII file and uploaded to the Swallow Gateway ${ }^{\mathrm{TM}}$ web- $^{\mathrm{T}}$ 109 application for analysis (57).

\section{Test bolus formulation and swallow protocol}

111 Participants were fasted for a minimum of three hours, and prior to catheter positioning

112 Lidocaine spray (5\%) was applied to one nostril. Participants were tested while seated in a head

113 neutral, upright position. The HRPM protocol for each participant involved triplicate cued

114 swallow challenges across 12 liquid bolus conditions (total 36 swallows) administered via

115 syringe. The conditions comprised three consistencies (thin, mildly thick and extremely thick;

116 see below) and four volumes (3, 5, 10 and $20 \mathrm{ml})$. Prior to any bolus administration, participants

117 were informed to attempt single swallows per bolus through the study, however, were assured

118 that multiple swallows were not to be avoided if felt to be required. The fluid consistencies for

119 the protocol were prepared using the Standardized Bolus Medium (SBMkit) product (Trisco Pty

120 Ltd, Australia), purpose-formulated to optimize stable bolus electrical conductivity properties

121 across all bolus consistencies, ensuring reliability of impedance-based measurements. The

122 SBMkit comprises an apple flavored, sodium chloride ( $\mathrm{NaCl})$ concentrate solution, and a 
123 separate gum-based thickener (Precise Thick'N Instant), which during preparation are added to

124 tap water. The International Dysphagia Diet Standardization Initiative (IDDSI) protocols (59)

125 were used to confirm mildly thick (IDDSI level 2 by 10 second syringe drip test) and extremely

126 thick (IDDSI level 4 by spoon tilt test), and a HAAKE Viscotester 550TM viscometer (Thermo

127 Electron, Karlsruhe, Germany) was used to assess the shear viscosity values of $137.37 \pm 5.16$

$128 \mathrm{mPa} \cdot \mathrm{s}$ (IDDSI 2) and $637.49 \pm 33.71 \mathrm{mPa} \cdot \mathrm{s}$ (IDDSI 4) at $50 \mathrm{~s}^{-1}$ (batch number 59676), by using

$129 \quad 10.27 \mathrm{~g}$ and $30.83 \mathrm{gr}$ in ionic solution till $200 \mathrm{ml}$.

130 Swallow Gateway analysis

131 Data were exported to the Swallow Gateway ${ }^{\mathrm{TM}}$ online application for analysis 132 (www.swallowgateway.com; owned and provided by Flinders University, Adelaide, South

133 Australia). Swallow analysis was conducted by author LF and cross-checked by author TO.

134 While blinded analysis would be optimal, bias is minimized by the semi-automated swallow 135 analysis methods. Results were generated in accordance with a recommended core outcome 136 set (39), and novel (additional to core outcome set) Swallow Gateway ${ }^{\mathrm{TM}}$-specific metrics were 137 also derived; see Table 1 for a complete list of parameters and definitions. For the most part, 138 the recommended core outcome set describes four key types of bio-mechanical phenomena: 139 lumen occlusive pressures at the velopharynx, mesopharynx, hypopharynx, and UES; 140 hypopharyngeal intrabolus pressures (IBP); UES opening extent, and UES relaxation. Analytic 141 methods and reliability of Swallow Gateway ${ }^{\mathrm{TM}}$ analysis have previously been described (57). 142 Pharyngeal swallows are selected from the manometric tracing and labelled according to bolus 143 administration. In this study, piecemeal swallows were excluded from analysis as a reduction in 144 bolus volume seen with piecemeal swallows is known to alter swallow biomechanics. Figure $1 \mathrm{~A}$ 145 demonstrates the selection of spatial and temporal landmarks, which define the boundaries for 146 semi-automated analysis. Swallow parameters that have previously been correlated with 
147 pathophysiological outcomes, e.g. radiologically confirmed aspiration $(6,41,55)$, are then

148 derived.

\section{Statistical analysis}

150 The average results for each of the 12 swallow test conditions were tabulated in an Excel 151 spreadsheet for statistical analysis using SPSS (IBM Corp. IBM Statistical Package for the

152 Social Sciences [SPSS] Statistics for Windows, v. 25.0 Armonk, NY: IBM Corp). Data with a 153 skewed distribution were normalized by log transformation prior to analysis. The main effects of 154 volume, viscosity, age and gender were evaluated using generalized linear mixed model. 155 Bonferroni adjustment was applied to pairwise comparisons.

\section{Results}

158 Fifty healthy volunteers (mean age 46yrs; age range 19-78yrs old; 29 females, 21 males) were 159 included in this study and group characteristics are outlined in Table 2. Participants were 160 grouped $<60 y$ rs or $>60 y$ rs as age related changes in healthy swallowing have been shown to 161 commence around 60 years of age $(11,14,20,33,53)$. The manometry procedure was well162 tolerated across the cohort. One participant had difficulties with the catheter in situ, therefore a 163 limited number of swallows were acquired for this subject. Piecemeal swallowing, whereby the 164 orally administered bolus is swallowed in portions, rather than in whole, was observed for 38 165 swallows (6\%) across 27 individuals. Results from piecemeal swallows were removed to ensure 166 the data in this study represent single swallow bolus transfer per volume given. However, 167 normal reference ranges of un-cued piecemeal swallowing across larger bolus volumes in future 168 studies would have clinical utility. All results for main effects are presented in Table 3. 
170 Pharyngeal Lumen occlusive pressures: Pharyngeal, Velopharyngeal, Mesopharyngeal, 171 and Hypopharyngeal Contractile Integrals

172 Lumen occlusive pressures measured as contractile integrals $(\mathrm{Cl})$ of the pharynx were 173 augmented as bolus volume increased. Pairwise comparisons are displayed in Figure 2A. A 174 significant main effect of volume was observed for contractility at the level of velopharynx $(\mathrm{VCI})$ $175(\mathrm{~F}=9.27, \mathrm{p}<0.001)$, and hypopharynx $(\mathrm{HPCl})(\mathrm{F}=2.87, \mathrm{p}=0.04)$ (Table 3). Pairwise differences 176 between volumes were observed for $\mathrm{VCl}$ (Figure 2A). Viscosity did not affect pharyngeal 177 contractility (see Table 3 and Figure 2A). Age did not affect overall pharyngeal contractility as 178 defined by $\mathrm{PhCl}$, however, older subjects demonstrated evidence of reduced velo- and 179 mesopharyngeal contractility $(F=7.29, p<0.007$, and $F=8.98, p=0.003$ respectively; Table 3$)$. A 180 large gender effect was seen, with male participants showing greater contractility of the pharynx 181 overall $(\mathrm{F}=95.24, \mathrm{p}<0.001)$, as well as greater velo- and mesopharyngeal contractility compared 182 to female participants $(F=54.87, p<0.001$ and $F=181.2, p<0.001$ respectively).

\section{Hypopharyngeal intrabolus pressure}

184 Hypopharyngeal intrabolus pressures (IBP) were altered by both increased volumes and 185 viscosity (main effects $F=26.30, p<0.001$, and $F=10.49, p<0.001$ respectively). Significant 186 pairwise differences were observed across all volume combinations with greater IBP observed 187 with larger volumes $(p<0.005)$ and viscosity combinations (IDDSI level 0 vs. level $2 p=0.03$, vs. 188 level $4 p<0.001$, and level 2 vs. level $4 p<0.05$ ) (Figure 2D). Older subjects showed a trend 189 towards higher IBP values $(F=3.36, p=0.07)$, while male subjects demonstrated overall lower 190 IBP values compared to females $(F=12.06 p=0.001)$. 
192 Like IBP, UES integrated relaxation pressures (UES IRP) demonstrated significant main effects 193 seen with increased UES IRP observed for increased volume and viscosity $(F=43.47, p<0.001$ 194 and $F=35.93, p<0.001$, respectively). Significant pairwise differences are depicted in Figure 2D. 195 UES IRP increased with age $(F=21.71, p<0.001)$, and, in contrast to the IBP, was higher in male 196 vs female subjects $(F=9.03, p=0.003)$.

\section{UES relaxation duration and opening extent: UES max. admittance, UES relaxation time}

198 UES relaxation time increased with higher bolus volume swallows (main effect $\mathrm{F}=32.87$,

$199 \mathrm{p}<0.001$; see Figure 2 for pairwise comparisons) but was reduced during heavier viscosity 200 swallows $(F=9.25, p<0.001)$. UES opening, as measured using UES maximum admittance (UES

201 max ad), revealed the most sensitive findings across this study based on the size of main effect 202 and number of pairwise differences. Both volume and viscosity increase the UES max ad $203(\mathrm{~F}=383.2, \mathrm{p}<0.001$ and $\mathrm{F}=51.84, \mathrm{p}<0.001$ respectively; pairwise comparisons are shown in 204 Figure 2D).

\section{Additional swallow function variables}

UES Contractile Pressures: UES basal pressure, UESCI, UES peak pressure and Proximal 207 Esophageal Contractile Integral

208 A small numerical increase in pre-swallow UES basal pressure was seen with larger bolus 209 volumes (Figure 2C), however this did not reach significance. In contrast, bolus viscosity had a 210 significant main effect in reducing UES basal pressure $(F=10.08, p<0.001)$, with pairwise 211 significance for $10 \mathrm{ml}$ volumes only IDDSI level 0 vs. level $2 ; p=0.05$, level $4, p=0.02$ (Figure 2C). 212 A significant increase in post-swallow activity of the UES was observed with larger bolus sizes 213 as demonstrated based on a higher UES contractile integral (UESCI) (main effect F=4.78, 
$214 p=0.003$ ), and UES peak pressure (main effect $F=3.98, p=0.008$ ). Pairwise differences between

215 volumes were observed for UESCI nor UES peak pressure (see Figure 2B). Viscosity affected 216 neither UESCI, nor UES peak pressure.

217 Age had no effect on UES basal pressure or UESCI, but a significant increase in UES peak 218 pressure was seen for participants $>60 y r s(F=38.13, p<0.001)$. Male subjects demonstrated a 219 significantly higher UES basal pressure, UES peak pressure and UESCI compared to female 220 participants $(F=69.40, p<0.001, F=50.14, p<0.001$, and $F=83.73, p<0.001$ respectively).

221 The activity of the proximal esophagus was highly responsive to bolus conditions, with proximal 222 esophageal contractile integral $(\mathrm{PCl})$ increasing with both volume (main effect $\mathrm{F}=20.13$, $223 \mathrm{p}<0.001$ ) and viscosity (main effect $\mathrm{F}=7.88, \mathrm{p}<0.001$ ) (Figure 2B). Age had no effect on $\mathrm{PCl}$,

224 however male subjects had significantly increased $\mathrm{PCl}$ measurements compared to female 225 participants $(F=20.22, p<0.001)$.

226 Pharyngeal Flow Timing and Bolus Presence: DCL and BPT

227 There were significant main effects of volume and viscosity on timing variables. Distension to 228 contraction latency (DCL) and bolus presence time (BPT) were lengthened by volume $(F=71.93$, $229 \mathrm{p}<0.001$ and $\mathrm{F}=31.61, \mathrm{p}<0.001$ respectively) and were shortened by viscosity $(\mathrm{F}=14.09$, $230 \mathrm{p}<0.001$ and $\mathrm{F}=8.59, \mathrm{p}<0.001$ ) (Figure $2 \mathrm{E}$ ). Age had no effect on $\mathrm{DCL}$ and $\mathrm{BPT}$, but a 231 significant gender effect $(F=5.35, p=0.02$ and $F=14.00, p<0.001)$ was observed with male 232 participants showing increased DCL compared to females.

\section{Swallow Risk Index: SRI}

234 Swallow Risk Index (SRI), a global composite score designed to capitalize on the directionality 235 of aberrant swallow parameters, increased as bolus volume and viscosity increased (main 
236 effects $F=31.71, p<0.001$ and $F=3.19, p=0.04$ respectively). The $S R I$ increased in older age 237 groups $(F=4.55, p=0.03)$ and was reduced in males $(F=3.98, p=0.05)$.

\section{Discussion}

240 In this study, we utilized a unidirectional sensor state-of-the-art manometry-impedance

241 technique to characterize the oro-pharyngeal swallow response in relation to a wide range of 242 bolus conditions using an extensive series of established swallow function parameters. The

243 main findings were: i) the healthy swallow response was overall more finely tuned and modified

244 in relation to bolus volume than bolus viscosity, with larger boluses leading to greater pressure 245 generation, ii) the parameters quantifying bolus distension area, distension pressure and 246 distension timing were more sensitive than contractile measures, for detecting bolus-related

247 modulation of the swallow system, iii) viscosity changes were found to alter UES pre-swallow 248 basal pressure, bolus flow timing and UES relaxation duration, and iv) age and gender effects 249 were also seen, most notably, a decrease in pharyngeal contractility with age and reduced UES 250 relaxation in older and male participants. Altogether these findings define the biomechanical 251 features associated with the oro-pharyngeal swallow response in health, providing a benchmark 252 for assessment of these features in patients with OPD.

253 Pharyngeal, UES and proximal esophageal contractility measures

254 With increasing bolus volumes, we observed modulatory responses to pharyngeal contractility.

255 The largest increases were seen in the velo-pharyngeal contractile integral (VCI), reflecting 256 pressures that seal the pharyngeal chamber proximally, which is in line with previous research $257(14,33,53)$. The observed change in contractility indicates greater force generation as a larger 258 bolus volume is propelled. UES post swallow pressures also increased with increasing bolus 
volumes; and it has been suggested that this contraction helps to prevent retrograde bolus 260 return immediately post swallow (47). Of interest, increased bolus viscosity had little or no effect 261 on the $\mathrm{VCl}$ or any other pharyngeal contractility measurements. This is in line with some 262 previous work $(33,53)$, while others have reported reduced pharyngeal contractility, measured 263 as maximum pressure values, with increased viscosity (23). In relation to the hypopharynx 264 specifically, the current study detected a small overall increase in hypopharyngeal contractility 265 with increasing volume, and increased hypopharyngeal IBP was also observed. This is in line 266 with previous research (13), and is discussed below. We believe a larger sample size in this 267 current study may have revealed the subtle pharyngeal contractility changes we note.

268 Overall, our findings have demonstrated a more pronounced stimulus from bolus volume, 269 compared to bolus viscosity for modulation of the pharyngeal swallowing motor program. 270 However, interestingly, the pre-relaxation UES basal pressure was significantly augmented for 271 thinner bolus consistencies, an effect that was most pronounced at $10 \mathrm{ml}$ volumes, and while 272 this is not widely documented it corresponds with another recent report (23). This may suggest 273 an anticipatory activation of the UES during the earliest phases of the swallow motor response 274 i.e. in concert with earlier onset of hyolaryngeal excursion and earlier CP muscle relaxation that 275 occur to accommodate thinner fluids, which arrive earlier at the airway opening (8). 276 Furthermore, an element of UES volitional control has recently been shown, whereby healthy 277 volunteers were trained with manometric biofeedback to elevate or reduce UES pressure (34). 278 This suggests that pre-swallow UES basal pressure may be influenced by preparatory central 279 and possible volitional factors. In general, the UES pre-swallow contraction is thought to assist 280 in the creation of negative pressures within the proximal esophagus which, upon UES opening, 281 causes a bolus suction effect that facilitates bolus transfer into the esophagus $(18,29,43)$. This 282 suction effect is associated with negative nadir UES relaxation pressures, a biomechanical 283 feature which was apparent in our participants, particularly during smaller volume swallows. 
284 Observations in relation to proximal peristalsis of the esophageal body are not widely reported 285 in the literature when compared to the pharynx and distal esophagus. However, in the current 286 study, we observed marked effects of bolus condition on proximal esophageal contractility. 287 Indeed, the proximal esophageal contractile integral $(\mathrm{PCl})$ was by far the most responsive of all 288 reported contractile measures, increasing significantly with both liquid volume size and viscosity 289 level. Experimental luminal fluid distention of the esophagus in isolation is well known to initiate 290 secondary peristalsis as well as a range of other specific esophageal and UES contractile 291 reflexes governed by central and enteric nervous system circuits $(4,14,24,53,56)$. Activation 292 of some mechanoreceptor-initiated peripheral circuits is also likely to occur during volitional 293 bolus swallowing. Their effects are potentially superimposed leading to alteration of the 294 esophageal contractile response. Our data show that the fluid bolus conditions that generated

295 the highest lumen distension pressures during bolus transport were associated with the greatest 296 level of proximal esophageal contractile response. Importantly, the broad-based responsiveness 297 of the proximal esophagus to physiological bolus distensions differed to the pharyngeal regions 298 which only showed volume-related increases in contractility, despite viscosity level also being a 299 potent driver for distension pressure, as is described below.

301 Using a variety of acquisition methods, measurements and swallow protocols, previous 302 research has established that larger bolus volumes are associated with higher pharyngeal 303 distension pressures and longer UES opening to accommodate earlier arrival of the bolus (4, $30414,53,56)$. Results from this study highlight three metrics (each relating to the proficiency of 305 UES relaxation and opening), which responded significantly to increases in volume and 306 viscosity. These were: i. hypopharyngeal intrabolus pressure (IBP), ii. UES maximum 307 admittance, and iii. UES integrated relaxation pressure (IRP). Age and gender effects in this 308 study also confirm their sensitivity for detecting subtle changes within an otherwise normally 
309 functioning system $(33,38)$. Our results suggest these metrics are key markers of swallow 310 modulation.

311 Elevated hypopharyngeal intrabolus pressure is known to flag possible UES outflow obstruction

312 in patients as upstream hypopharyngeal pressures elevate with increased viscosity, increased

313 trans-sphincteric bolus flow rate, reduced UES aperture, and/or reduced hypopharyngeal and/or

314 UES distensibility $(18,46,63)$. The observed effects of age and gender possibly indicate a

315 subtle reduction in compensatory reserve in older individuals, and possibly larger pharyngeal

316 chambers overall in males able to accommodate the bolus challenges with less impact on IBP

317 compared to female participants. Understanding normal IBP modulation may assist in

318 assessment and interpretation of difficult dysphagia cases with and without obvious features of

319 UES dysfunction.

320 UES maximum admittance, a marker of UES opening extent (5), detected differences at all 321 volume increments across all viscosity levels. This was the only metric able to distinguish 322 between 3 and $5 \mathrm{ml}$ volumes for both thin and mildly thickened fluids. Maximum admittance has 323 previously been described as a non-specific marker of reduced UES opening (5), with low 324 admittance values flagging impaired bolus driving forces and/or UES luminal restriction. 325 Additionally, the UES pressures during relaxation and reception of the propelled bolus (UES 326 IRP) were progressively elevated as the volume and viscosity increased, as has previously 327 been shown with high resolution manometry (33). With significant pairwise comparisons 328 between lower and higher volumes and consistencies, and differences for age and gender, the 329 sensitive alterations of UES opening and relaxation pressures demonstrate the potential for 330 these measures to be used to detect not only overt but also subtle swallow modulation 331 dysfunction.

\section{Flow timing measures}


333 The current study shows that distension, relaxation and contractility timing are key physiological

334 features of the pharyngeal swallow response that are substantially altered in relation to bolus 335 conditions. This is perhaps not surprising as the optimal timing and coordination of bolus arrival 336 with luminal opening and closure serves to minimize resistance to bolus flow and optimize 337 airway protection in a healthy swallow system $(10,13)$. The components of UES opening, 338 achieved by hyolaryngeal excursion, bolus propulsive forces and CP muscle deactivation are all 339 thought to be influenced by bolus volume, and modified via central pattern modulation in the 340 brainstem (4). In this study, UES relaxation time increased with larger bolus volume as has 341 been shown in previous work (27), whereas increasing bolus viscosity decreased UES 342 relaxation time in our study. It is likely that faster moving boluses, as seen with larger volumes 343 and thinner bolus types, are associated with an earlier onset of UES relaxation when compared 344 to a heavier and slower bolus (18); this has previously been shown in smaller volumes (23). In 345 contrast to our current findings, a recent radiological study of a <60yr old cohort reported no 346 effect of viscosity on UES opening duration. However, they showed swallow reaction time was 347 significantly later with thicker bolus types (60), and time to laryngeal vestibule closure was 348 shorter, both relative to a later hyoid elevation movement and a prompter airway protective 349 response once the hyoid movement commenced (60).

350 Pharyngeal distension is influenced by lingual propulsion, which facilitates timely arrival of a 351 cohesive bolus ahead of the pharyngeal stripping wave. Timing between pharyngeal distension 352 and contractility (DCL), and overall bolus presence time in the pharynx (BPT), revealed similar 353 results to UES relaxation time. Longer durations of DCL and BPT were seen in response to 354 larger volumes, however durations were shorter in response to increased viscosity. This can be 355 explained by the relatively later arrival of a thicker bolus into the pharyngeal chamber compared 356 to a thin fluid, which flows faster and therefore arrives comparatively 'earlier' in the swallow 357 sequence in relation to the pharyngeal contraction, which is largely stereotypical in its timing. 
Overall, this study demonstrates flow-timing metrics which are sensitive to volume changes and discriminated all increments for each separate viscosity level. All timing metrics are therefore 360 potentially useful clinical markers of aberrant swallow modulation and potentially useful markers 361 of swallow improvement when fluid viscosity is modified.

\section{Swallow Risk Index}

363 Finally, the SRI increased with volume, viscosity, age, and gender. The SRI has previously 364 proven useful in dysphagia assessment and has been proposed as a global marker of swallow 365 dysfunction $(5-7,54,55)$. Our study supports this concept, showing that the SRI has sufficient 366 sensitivity to detect bolus condition changes. The SRI increase, albeit within normal limits, seen 367 with increased viscosity is driven by a correlated increase in IBP and a reduced DCL measure 368 with more viscous boluses. These two individual metrics are responding as we would expect to 369 increased viscosity however, their contribution within the SRI formula amplifies the index 370 comparative to thin fluid swallows. In patients with evidence of pre-swallow pharyngeal bolus 371 presence, the SRI decreases with viscosity (40). Together with the subtle alterations related to 372 age and gender effects, our findings suggest an abnormal SRI may be a useful global measure 373 to detect inadequate swallow modulation.

$375 \quad$ Limitations

376 This study is limited in that measurements undertaken using HRPM with impedance were not 377 directly correlated with videofluoroscopy, as radiation exposure was unjustified. We note that 378 several previous manometry studies have reported and validated the physiological measures 379 against radiological outcomes in both healthy controls and patients with dysphagia, albeit with 380 varying acquisition methods and protocols $(29,32,41,46)$. Unidirectional pressure sensors 381 along the catheter assembly may have produced variability within pressure readings, therefore 
confirmation of these study findings with circumferential pressure sensor techniques will be 383 valuable in future studies. Bolus volumes and viscosity challenges in our study were undertaken 384 in a fixed order, rather than randomized protocol. Therefore, data may be subject to time and 385 order effects. With this extensive protocol, which spanned up to 30 minutes, sensory 386 accommodation may have influenced the results. Our findings must be interpreted in relation to 387 known viscosity-based rheological constructs. We have provided standardized measurements 388 with gum based thickening agent bolus preparations tailored to the IDDSI recommendations, 389 which can vary greatly within each broad IDDSI-based viscosity level, particularly between gum 390 vs. starch based thickening agents $(16,45,60)$. However, in this study the gum-based bolus 391 media underwent rheological testing at the IDDSI specified viscosities. We have included these 392 data for completeness and translatability. Future HRPM with impedance studies could explore 393 differences between gum and starch based thickening agents, and precise bolus rheological 394 characteristics such as elasticity, adhesiveness, cohesiveness (2) and shear thinning qualities $395(44,48)$, which may influence swallow biomechanics.

396 Strengths of the study were a sample size permitting adequately powered statistical analysis, 397 and balance for age and gender effects. This study adds to the current literature a 398 comprehensive report of healthy swallow modulation relating to a range of bolus volume and 399 viscosity conditions not previously reported. A set of normative values can now be referenced 400 within clinical practice. The use of www.swallowgateway.com software, now generalized for 401 routine use to derive consensus-recommended, as well as novel analytics, enables further 402 investigations across centers and study cohorts to both confirm and extend our findings. Beyond 403 the effects of texture modification and volume regulation, neuro-stimulants are increasingly 404 under investigation for their use as OPD treatments $(1,61)$ and future studies could explore the 405 biomechanical implications with HRPM and impedance methods. 
407 Describing swallow modulatory effects comprehensively in healthy participants, with a core 408 outcome set and a unified analysis system, represents a further step towards optimizing 409 diagnostic frameworks for oropharyngeal dysphagia. We report key swallowing modulation 410 measures in response to a thorough set of volume and viscosity ranges using standardized and 411 experimental HRPM and impedance parameters. Some findings of this study were confirmatory 412 of established knowledge, however other subtle and key differences not previously documented 413 are highlighted and present as important biomechanical indicators of healthy swallow 414 modulation. From the recommended core outcome set (39) hypopharyngeal intrabolus 415 pressure, UES maximum admittance, UES relaxation pressure and UES relaxation time, altered 416 most significantly with bolus condition. Further exploration in dysphagia patients will 417 substantiate these results and determine the clinical value of these measures which have 418 previously been difficult to achieve. 
Figure 1. Panel A: Example of a pressure topography swallow plot. Panel B: Integrated pharyngeal pressure profile and impedance/admittance curves. Panel C: Integrated UES pressure profile and impedance/admittance curves. Abbreviated pressure flow measures incorporated in the figure to correspond with definitions in Table 1.

Figure 2. Graphs showing effects of volume and viscosity for $A$ : pharyngeal contractility measures; B: UES contractility measures, and proximal esophageal contractility; C: UES Basal pressure; D: pharyngeal and UES distension measures; and E: Pressure flow Timing measures. * depicts Bonferroni adjusted pairwise significance vs. $20 \mathrm{ml}$ volumes; \# vs. $10 \mathrm{mls}$ and ${ }^{\wedge}$ vs. $5 \mathrm{mls}$. $a$ depicts Bonferroni adjusted pairwise significance vs. IDDSI level 0; $\boldsymbol{\Phi}$ vs. IDDSI level 2.

Table 1. Core Outcome Set Metrics and Additional to Core Outcome Set Metrics, with pressure-

Table 2. Participant characteristics from Group $1 \& 2$. Mean (range) results for swallow screening using the DAKKAK and SSQ questionnaires are presented. Mean (SD) for Core

437 Outcome Set and Additional to Core Outcome Set Metrics presented. \# indicates statistical 438 significance $(p<0.05)$ vs. Group 1.

Table 3. Summary of Main Effects from General Linear Mixed Modelling (GLMM) with F statistic 441 and $P$ values presented. $\uparrow$ indicates directionality of effect with increasing 442 volume/viscosity/age/male gender. *measures were log transformed prior to GLMM. Bold results indicate metrics which showed statistical significance following Bonferroni adjustments. 
1. Alvarez-Berdugo D, Rofes L, Casamitjana JF, Padron A, Quer M, and Clave P. Oropharyngeal and laryngeal sensory innervation in the pathophysiology of swallowing disorders and sensory stimulation treatments. Annals of the New York Academy of Sciences 1380: 104-120, 2016.

2. Bolivar-Prados M, Rofes L, Arreola V, Guida S, Nascimento WV, Martin A, Vilardell N, Ortega Fernández O, Ripken D, Lansink M, and Clavé P. Effect of a gum-based thickener on the safety of swallowing in patients with poststroke oropharyngeal dysphagia. Neurogastroenterology and Motility 31: 1-11, 2019.

3. Butler SG, Stuart A, Castell D, Russell G, Koch K, and Kemp S. Effects of Age, Gender, Bolus condition, Viscosity, and Volume on Pharyngeal, and Upper Esophageal Sphincter Pressure and Temporal Measurements During Swallowing. Journal of Speech, Language, and Hearing Research 52: 2009.

4. Cock, Jones C, Hammer M, Omari T, and McCulloch T. Modulation of Upper Esophageal Sphincter (UES) Relaxation and Opening During Volume Swallowing. Dysphagia 19, 2016.

5. Cock C, Besanko L, Kritas S, Burgstad CM, Thompson A, Heddle R, Fraser RJ, and Omari TI. Maximum upper esophageal sphincter (UES) admittance: A non-specific marker of UES dysfunction. Neurogastroenterology and Motility 28: 225-233, 2016.

6. Cock C, and Omari T. Diagnosis of Swallowing Disorders: How We Interpret Pharyngeal Manometry. Current Gastroenterology Reports 19: 2017.

7. Cock C, and Omari T. Systematic review of pharyngeal and esophageal manometry in healthy or dysphagic older persons (>60 years). Geriatrics (Switzerland) 3: 2018.

8. Cook I, Dodds W, Dantas RO, Massey B, Kern MK, Lang IM, Brasseur JG, and Hogan WJ. Opening mechanism of the human upper esophageal sphincter Opening mechanisms of the human upper esophageal sphincter. The American Journal of Physiology G748-G759, 1989.

9. Cook IJ. Combined pharyngeal Impedance-Manometry: Has it finally come of age? Clinical Gastroenterology and Hepatology 9: 813-815, 2011.

10. Cook IJ, Dodds WJ, Dantas RO, Kern MK, Massey BT, Shaker R, and Hogan WJ. Timing of videofluoroscopic, manometric events, and bolus transit during the oral and pharyngeal phases of swallowing. Dysphagia 4: 8-15, 1989.

11. Cook IJ, Weltman MD, Wallace K, Shaw DW, McKay E, Smart RC, and Butler SP. Influence of aging on oral-pharyngeal bolus transit and clearance during swallowing: Scintigraphic study. American Journal of Physiology - Gastrointestinal and Liver Physiology 266: 972-977, 1994.

12. Dakkak M, and Bennett JR. A new dysphagia score with objective validation. 1992, p. 99-100.

13. Dantas RO, Kern MK, Massey BT, Dodds WJ, Kahrilas PJ, Brasseur JG, Cook IJ, and Lang IM. Effect of swallowed bolus variables on oral and pharyngeal phases of swallowing. The American journal of physiology 258: G675-G681, 1990.

14. Ferris L, Schar M, McCall L, Doeltgen S, Scholten I, Rommel N, Cock C, and Omari T. Characterization of swallow modulation in response to bolus volume in healthy subjects accounting for catheter diameter. The Laryngoscope 1-7, 2017.

15. Ghosh SK, Pandolfino JE, Zhang Q, Jarosz A, and Kahrilas PJ. Deglutitive upper esophageal sphincter relaxation: a study of 75 volunteer subjects using solid-state highresolution manometry. American journal of physiology Gastrointestinal and liver physiology 291: G525-531, 2006. 
16. Hanson B. A review of diet standardization and bolus rheology in the management of dysphagia. Current Opinion in Otolaryngology and Head and Neck Surgery 24: 183-190, 2016. 17. Hoffman MR, Ciucci MR, Mielens JD, Jiang JJ, and McCulloch TM. Pharyngeal swallow adaptations to bolus volume measured with high-resolution manometry. The Laryngoscope 120: 2367-2373, 2010.

499

500

501

502

503

504

18. Jacob P, Kahrilas PJ, Logemann JA, Shah V, and Ha T. Upper esophageal sphincter opening and modulation during swallowing. Gastroenterology 97: 1469-1478, 1989.

19. Jean A. Brain stem control of swallowing: neuronal network and cellular mechanisms. Physiological reviews 81: 929-969, 2001.

20. Jiao H, Mei L, Sharma T, Kern M, Sanvanson P, and Shaker R. A human model of restricted upper esophageal sphincter opening and its pharyngeal and UES deglutitive pressure phenomena. American journal of physiology Gastrointestinal and liver physiology 311: G84-90, 2016.

509 21. Jones CA, Meisner EL, Broadfoot CK, Rosen SP, Samuelsen CR, and McCulloch

510 TM. Methods for Measuring Swallowing Pressure Variability Using High-Resolution Manometry.

511 Frontiers in Applied Mathematics and Statistics 4: 1-17, 2018.

512 22. Knigge MA, and Thibeault S. Relationship Between Tongue Base Region Pressures 513 and Vallecular Clearance. Dysphagia 31: 391-397, 2016.

514 23. Lan Y, Xu GQ, Yu F, Lin T, Jiang LS, and Liu F. The effect of bolus consistency on 515 swallowing function measured by high-resolution manometry in healthy volunteers. 516 Laryngoscope 127: 173-178, 2017.

24. Lang IM, Medda BK, and Shaker R. Characterization and mechanism of the esophagoesophageal contractile reflex of the striated muscle esophagus. American journal of physiology Gastrointestinal and liver physiology 317: G304-G313, 2019.

25. Lee TH, Lee JS, and Kim WJ. High resolution impedance manometric findings in dysphagia of Huntington's disease. World journal of gastroenterology : WJG 18: 1695-1699, 2012.

26. Lee TH, Lee JS, Park JW, Cho SJ, Hong SJ, Jeon SR, Kim WJ, Kim HG, Cho JY, and Kim JO. High-resolution impedance manometry facilitates assessment of pharyngeal residue and oropharyngeal dysphagic mechanisms. Diseases of the Esophagus 27: 220-229, 2014.

27. Lin T, Xu G, Dou Z, Lan Y, Yu F, and Jiang L. Effect of bolus volume on pharyngeal swallowing assessed by high-resolution manometry. Physiology and Behavior 128: 46-51, 2014. 28. Logemann JA. Evaluation and Treatment of Swallowing Disorders. Austin Texas: ProEd An International Publisher, 1998.

29. May NH, Davidson KW, Pearson WG, and O'Rourke AK. Pharyngeal swallowing mechanics associated with upper esophageal sphincter pressure wave. Head and Neck 9-11, 2019.

30. Meyer JP, Jones CA, Walczak CC, and McCulloch TM. Three-dimensional manometry of the upper esophageal sphincter in swallowing and nonswallowing tasks. Laryngoscope 126: 2539-2545, 2016.

31. Mielens JD, Hoffman MR, Ciucci MR, Jiang JJ, and McCulloch TM. Automated analysis of pharyngeal pressure data obtained with high-resolution manometry. Dysphagia 26: 3-12, 2011.

32. Nativ-Zeltzer N, Kahrilas PJ, and Logemann JA. Manofluorography in the evaluation of oropharyngeal dysphagia. Dysphagia 27: 151-161, 2012.

33. Nativ-Zeltzer N, Logemann JA, Zecker SG, and Kahrilas PJ. Pressure topography metrics for high-resolution pharyngeal-esophageal manofluorography-a normative study of younger and older adults. Neurogastroenterology and Motility 28: 721-731, 2016. 
34. Nativ-Zeltzer N, Belafsky PC, Bayoumi A, and Kuhn MA. Volitional control of the upper esophageal sphincter with high-resolution manometry driven biofeedback. Laryngoscope Investigative Otolaryngology 4: 264-268, 2019.

35. Newman R, Vilardell N, Clavé P, and Speyer R. Effect of Bolus Viscosity on the Safety and Efficacy of Swallowing and the Kinematics of the Swallow Response in Patients with Oropharyngeal Dysphagia: White Paper by the European Society for Swallowing Disorders (ESSD). Dysphagia 31: 232-249, 2016.

36. Nguyen NQ, Holloway RH, Smout AJ, and Omari TI. Automated impedancemanometry analysis detects esophageal motor dysfunction in patients who have non-obstructive dysphagia with normal manometry. Neurogastroenterology and motility : the official journal of the European Gastrointestinal Motility Society 25: 238-245, e164, 2013.

37. Omari T, Ferris L, Dejaeger E, Tack J, Vanbeckevoort D, and Rommel N. Upper esophageal sphincter impedance as a marker of sphincter opening diameter. American journal of physiology Gastrointestinal and liver physiology 302: G909-913, 2012.

38. Omari T, Tack J, and Rommel $\mathbf{N}$. Impedance as an adjunct to manometric testing to investigate symptoms of dysphagia: What it has failed to do and what it may tell us in the future. United European gastroenterology journal 2: 355-366, 2014.

39. Omari TI, Ciucci M, Gozdzikowska K, Hernández E, Hutcheson K, Jones C, Maclean J, Nativ N, Emily Z, Nicole P, Pulia R, Rommel N, and Rourke AO. High Resolution Pharyngeal Manometry and Impedance : Protocols and Metrics Recommendations of a High - Resolution Pharyngeal Manometry International Working Group. Dysphagia 2019.

40. Omari TI, Dejaeger E, Tack J, Van Beckevoort D, and Rommel N. Effect of bolus volume and viscosity on pharyngeal automated impedance manometry variables derived for broad dysphagia patients. Dysphagia 28: 146-152, 2013.

41. Omari TI, Dejaeger E, Van Beckevoort D, Goeleven A, Davidson GP, Dent J, Tack $\mathrm{J}$, and Rommel N. A method to objectively assess swallow function in adults with suspected aspiration. Gastroenterology 140: 1454-1463, 2011.

42. Omari TI, Dejaeger E, Van Beckevoort D, Goeleven A, De Cock P, Hoffman I, Smet MH, Davidson GP, Tack J, and Rommel N. A novel method for the nonradiological assessment of ineffective swallowing. The American journal of gastroenterology 106: 17961802, 2011.

43. Omari TI, Wiklendt L, Dinning P, Costa M, Rommel N, and Cock C. Upper esophageal sphincter mechanical states analysis: a novel methodology to describe UES relaxation and opening. Frontiers in systems neuroscience 8: 241-241, 2014.

44. Ong JJX, Steele CM, and Duizer LM. Challenges to assumptions regarding oral shear rate during oral processing and swallowing based on sensory testing with thickened liquids. Food Hydrocolloids 84: 173-180, 2018.

45. Ong JJX, Steele CM, and Duizer LM. Sensory characteristics of liquids thickened with commercial thickeners to levels specified in the International Dysphagia Diet Standardization Initiative (IDDSI) framework. Food Hydrocolloids 79: 208-217, 2018.

46. Pal A, Williams RB, Cook IJ, and Brasseur JG. Intrabolus pressure gradient identifies pathological constriction in the upper esophageal sphincter during flow. Am J Physiol Gastrointest Liver Physiol 285: G1037-G1048, 2003.

47. Pouderoux P, and Kahrilas PJ. Function of upper esophageal sphincter during swallowing: The grabbing effect. American Journal of Physiology - Gastrointestinal and Liver Physiology 272: 1997.

48. Qazi WM, Ekberg O, Wiklund J, Kotze R, and Stading M. Assessment of the FoodSwallowing Process Using Bolus Visualisation and Manometry Simultaneously in a Device that Models Human Swallowing. Dysphagia 34: 821-833, 2019. 
595

596

597

598

599

600

601

602

603

604

605

606

607

608

609

610

611

612

613

614

615

616

617

618

619

620

621

622

623

624

625

626

627

628

629

630

631

632

633

634

635

636

637

638

639

640

641

642

49. Regan J. Impact of Sensory Stimulation on Pharyngo-esophageal Swallowing Biomechanics in Adults with Dysphagia: A High-Resolution Manometry Study. Dysphagia 2020.

50. Robbins J, Nicosia M, Hind JA, Gill GD, Blanco R, and Logemann J. Defining Physical Properties of Fluids for Dysphagia Evaluation and Treatment. Perspectives on Swallowing and Swallowing Disorders (Dysphagia) 11: 16-19, 2002.

51. Rosen SP, Jones CA, and McCulloch TM. Pharyngeal swallowing pressures in the base-of-tongue and hypopharynx regions identified with three-dimensional manometry. The Laryngoscope 1-7, 2016.

52. Ryu JS, Park D, and Kang JY. Application and interpretation of high-resolution manometry for pharyngeal dysphagia. Journal of Neurogastroenterology and Motility 21: 283287, 2015.

53. Ryu JSo, Park D, Oh Y, Lee ST, and Kang JY. The effects of bolus volume and texture on pharyngeal pressure events using high resolution manometry and its comparison with videofluoroscopic swallowing study. Journal of neurogastroenterology and motility 22: 231-239, 2015.

54. Schar M, Woods C, Ooi EH, Athanasiadis T, Ferris L, Szczesniak MM, Cock C, and Omari T. Pathophysiology of swallowing following oropharyngeal surgery for obstructive sleep apnea syndrome. Neurogastroenterology and Motility 30: 1-11, 2018.

55. Schar MS, Omari TI, Fraser RJ, Bersten AD, and Bihari S. Disordered swallowing associated with prolonged oral endotracheal intubation in critical illness. Intensive Care Medicine 46: 140-142, 2020.

56. Sia I, Crary MA, Kairalla, John, Carnaby GD, Sheplak, Mark, and McCulloch T. Bolus volume and viscosity effects on pharyngeal swallowing power-How physiological bolus accommodation affects bolus dynamics. Neurogastroenterology \& Motility 2018.

57. Singendonk M, Cock C, Bieckmann L, Szczesniak M, Ferris L, Benninga M, and Omari T. Reliability of an online analysis platform for pharyngeal high-resolution impedance manometry recordings. Speech, Language and Hearing 22: 195-203, 2019.

58. Steele C, and Miller AJ. Sensory input pathways and mechanisms in swallowing: A review. Dysphagia 25: 323-333, 2010.

59. Steele CM, Namasivayam-MacDonald AM, Guida BT, Cichero JA, Duivestein J, Hanson B, Lam P, and Riquelme LF. Creation and Initial Validation of the International Dysphagia Diet Standardisation Initiative Functional Diet Scale. Archives of Physical Medicine and Rehabilitation 99: 934-944, 2018.

60. Steele CM, Peladeau-Pigeon M, Barbon CAE, Guida BT, Namasivayam-MacDonald AM, Nascimento WV, Smaoui S, Tapson MS, Valenzano TJ, Waito AA, and Wolkin TS. Reference values for healthy swallowing across the range from thin to extremely thick liquids. Journal of Speech, Language, and Hearing Research 62: 1338-1363, 2019.

61. Tomsen N, Alvarez-Berdugo D, Rofes L, Ortega O, Arreola V, Nascimento W, Martin A, Cabib C, Bolivar-Prados M, Mundet L, Legrand C, Clavé P, and Michlig S. A randomized clinical trial on the acute therapeutic effect of TRPA1 and TRPM8 agonists in patients with oropharyngeal dysphagia. Neurogastroenterology and Motility 1-12, 2020.

62. Wallace KL, Middleton S, and Cook IJ. Development and validation of a self-report symptom inventory to assess the severity of oral-pharyngeal dysphagia. Gastroenterology 118: 678-687, 2000.

63. Williams RBH, Wallace KL, Ali GN, and Cook IJ. Biomechanics of failed deglutitive upper esophageal sphincter relaxation in neurogenic dysphagia. American journal of physiology Gastrointestinal and liver physiology 283: G16-26, 2002. 
Downloaded from journals.physiology.org/journal/ajpgi at KU Leuven Univ Lib (134.058.253.030) on November 10, 2020. 

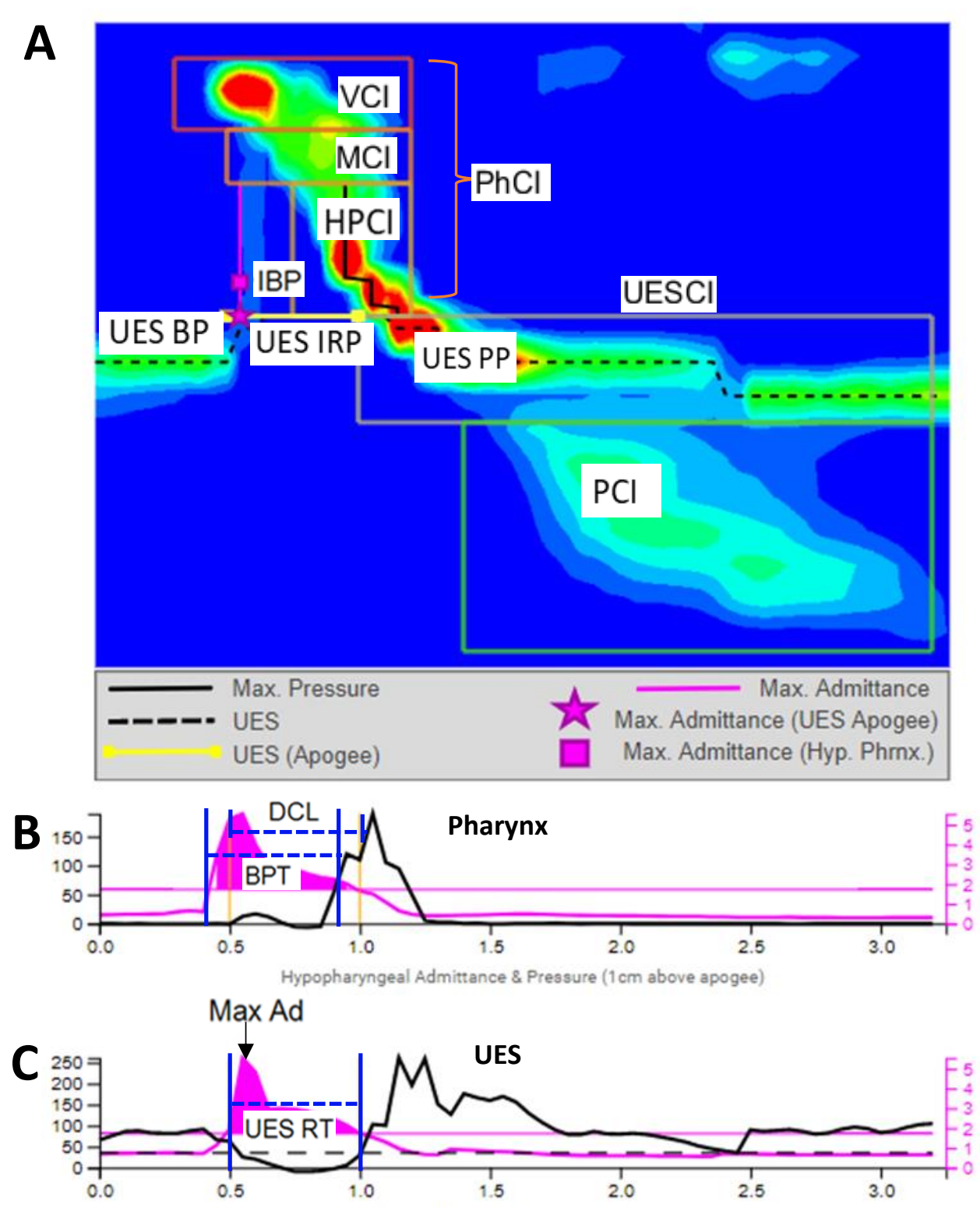


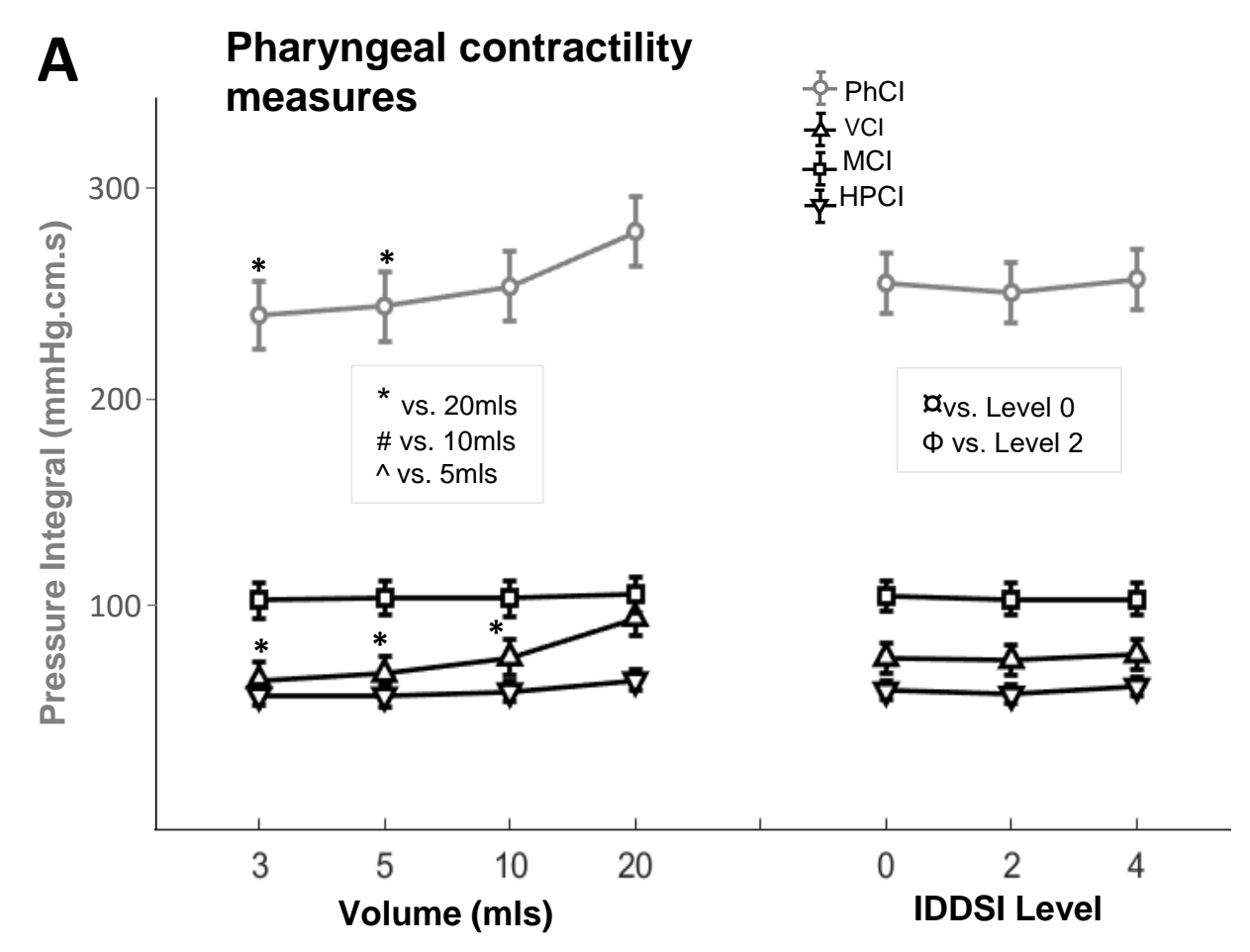




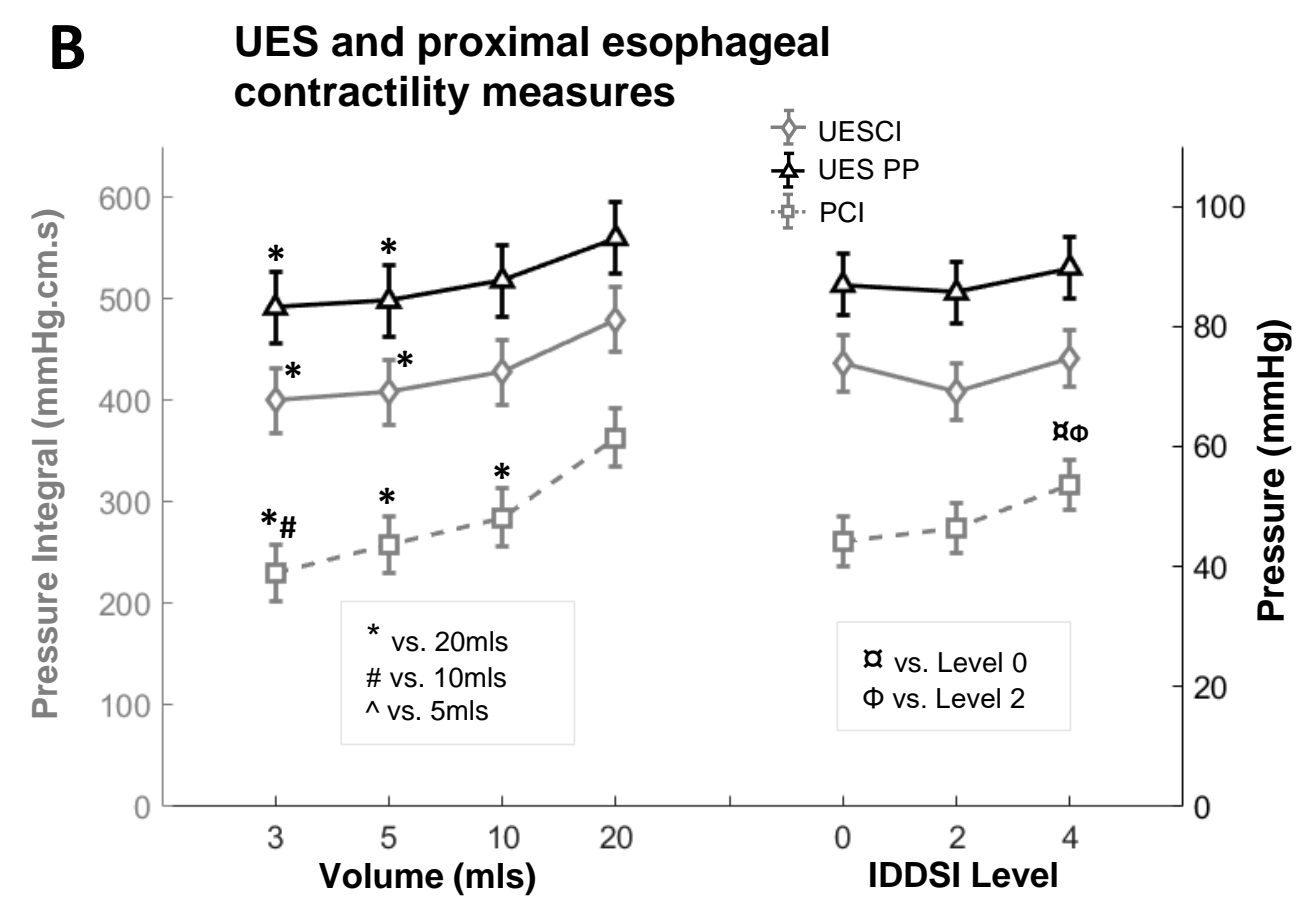




\section{UES basal pressure}

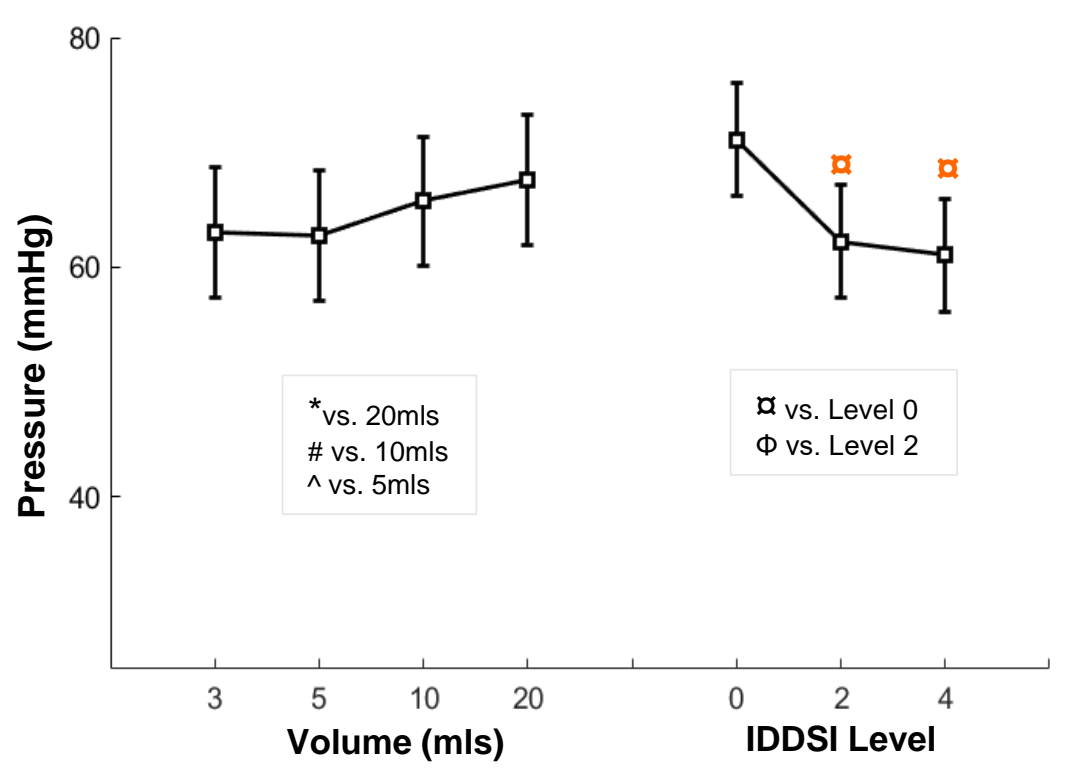




\section{Pharyngeal and UES distension measures}

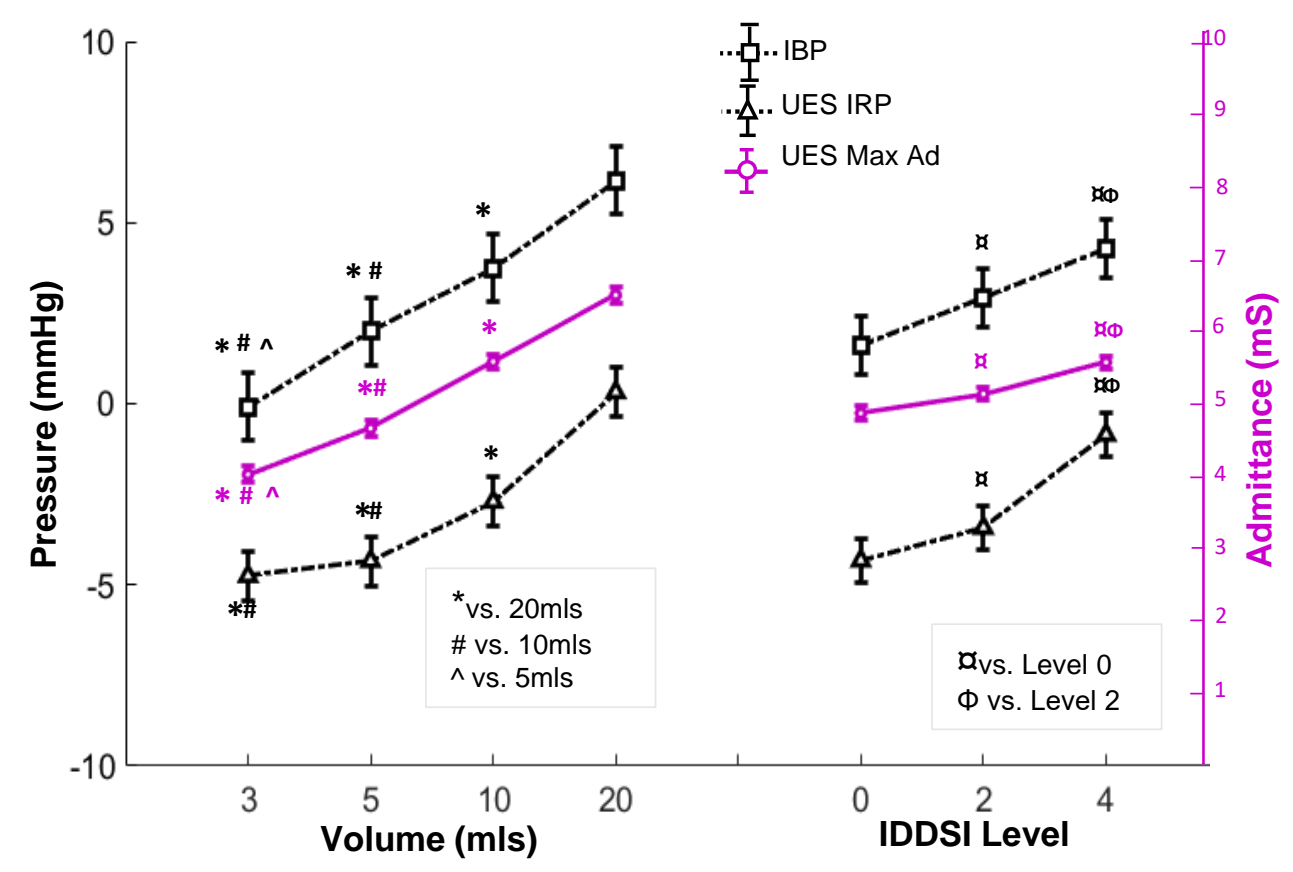




\section{E Pressure flow timing measures}

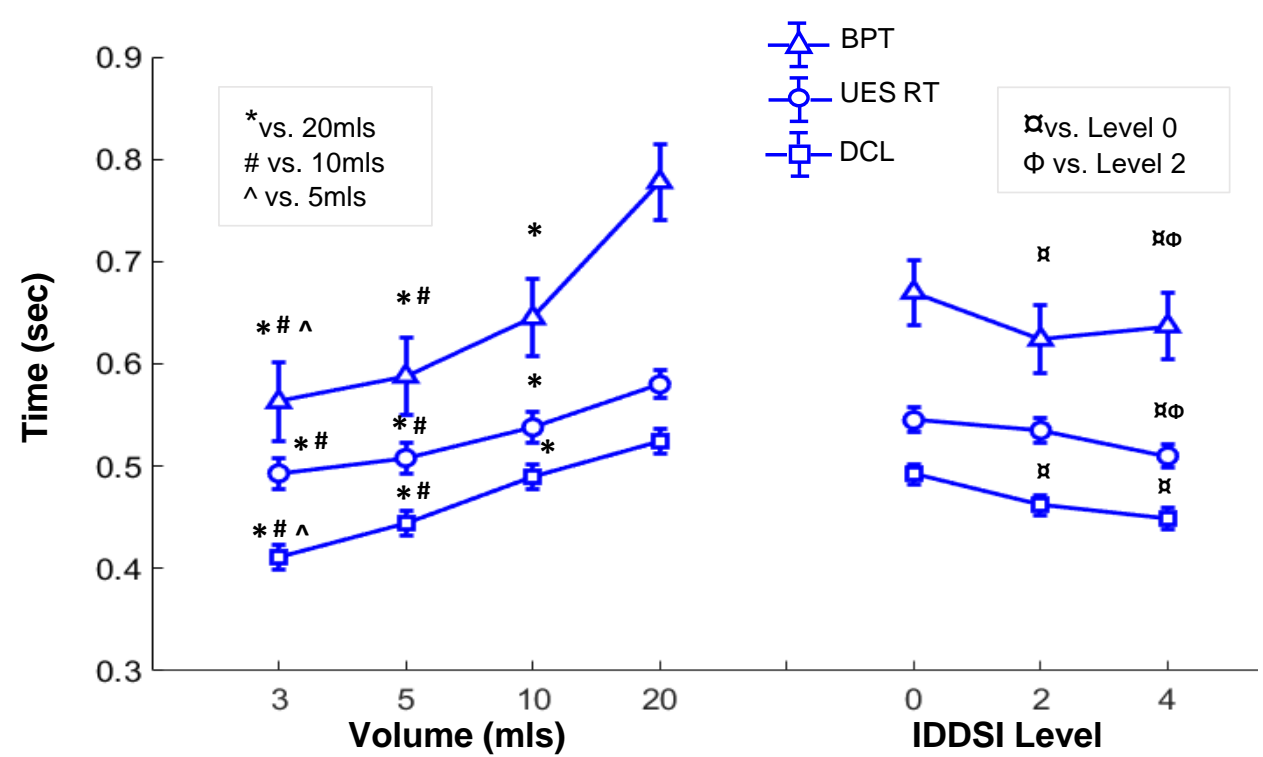




\begin{tabular}{|c|c|c|}
\hline \multicolumn{3}{|c|}{ CORE OUTCOME SET METRICS } \\
\hline $\begin{array}{l}\text { Measurement } \\
\text { Subtype }\end{array}$ & Measurement & Definitions (28) \\
\hline \multirow[t]{4}{*}{$\begin{array}{l}\text { Pharyngeal lumen } \\
\text { occlusive pressures }\end{array}$} & $\begin{array}{l}\text { Pharyngeal contractile } \\
\text { integral }(\mathrm{PhCl})\end{array}$ & $\begin{array}{l}\text { An integral pressure measure of } \\
\text { pharyngeal contractile vigor spanning } \\
\text { from the velopharynx to the upper } \\
\text { margin of the UES (mmHg.cm.s). }\end{array}$ \\
\hline & $\begin{array}{c}\text { Velopharyngeal contractile } \\
\text { integral }(\mathrm{VCl})\end{array}$ & $\begin{array}{l}\text { An integral pressure measure of } \\
\text { pharyngeal contractile vigor spanning } \\
\text { the velopharyngeal region only } \\
\text { (mmHg.cm.s). }\end{array}$ \\
\hline & $\begin{array}{c}\text { Mesopharyngeal } \\
\text { contractile integral (MCl) }\end{array}$ & $\begin{array}{l}\text { An integral pressure measure of } \\
\text { pharyngeal contractile vigor spanning } \\
\text { the mesopharyngeal region only } \\
(\mathrm{mmHg} . \mathrm{cm} . \mathrm{s}) \text {. }\end{array}$ \\
\hline & $\begin{array}{c}\text { Hypopharyngeal } \\
\text { contractile integral (HPCI) }\end{array}$ & $\begin{array}{l}\text { An integral pressure measure of } \\
\text { pharyngeal contractile vigor spanning } \\
\text { the hypopharyngeal region only } \\
\text { (mmHg.cm.s). }\end{array}$ \\
\hline $\begin{array}{l}\text { Hypopharyngeal } \\
\text { intrabolus } \\
\text { distension pressure }\end{array}$ & $\begin{array}{l}\text { Hypopharyngeal intrabolus } \\
\text { distension pressure (IBP) }\end{array}$ & $\begin{array}{l}\text { The pressure } 1 \mathrm{~cm} \text { superior to the UES } \\
\text { apogee position at the time of maximum } \\
\text { hypopharyngeal distension (indicated by } \\
\text { impedance/admittance) ( } \mathrm{mmHg} \text { ). }\end{array}$ \\
\hline \multirow[t]{3}{*}{$\begin{array}{c}\text { UES relaxation \& } \\
\text { opening }\end{array}$} & $\begin{array}{l}\text { UES integrated relaxation } \\
\text { pressure (UES IRP) }\end{array}$ & $\begin{array}{l}\text { A pressure measure of the extent of } \\
\text { UES relaxation pressure, generated as } \\
\text { the median of the lowest pressure in a } \\
\text { non-consecutive } 0.20-0.25 \text { second } \\
\text { window }(\mathrm{mmHg}) \text {. }\end{array}$ \\
\hline & $\begin{array}{l}\text { UES relaxation time } \\
\quad(\text { UES RT) }\end{array}$ & $\begin{array}{l}\text { A measure of the duration of UES } \\
\text { relaxation - a pressure interval below } \\
50 \% \text { of baseline or } 35 \mathrm{mmHg} \text {, whichever } \\
\text { is lower, in units of seconds (s). }\end{array}$ \\
\hline & $\begin{array}{c}\text { UES maximum admittance } \\
\text { (UES Max Ad) }\end{array}$ & $\begin{array}{l}\text { A measure of extent of UES opening. } \\
\text { The highest admittance value (inverse of } \\
\text { impedance) recorded during trans- } \\
\text { sphincteric bolus flow, in units of } \\
\text { millisiemens (mS). }\end{array}$ \\
\hline
\end{tabular}




\begin{tabular}{|c|c|c|}
\hline \multicolumn{3}{|c|}{ ADDITIONAL TO CORE OUTCOME SET SWALLOW GATEWAY ${ }^{\mathrm{TM}}$ SPECIFIC METRICS } \\
\hline $\begin{array}{l}\text { Variable } \\
\text { Subtype }\end{array}$ & Variable & Definition \\
\hline \multirow{3}{*}{$\begin{array}{l}\text { UES contractile } \\
\text { measure }\end{array}$} & $\begin{array}{l}\text { Upper esophageal } \\
\text { sphincter contractile } \\
\text { integral (UESCl) } \\
\end{array}$ & $\begin{array}{l}\text { An integral pressure measure of UES contractile vigor, post } \\
\text { swallow (mmHg.cm.s). }\end{array}$ \\
\hline & $\begin{array}{l}\text { UES basal pressure } \\
\text { (UES BP) }\end{array}$ & The peak pressure at the level of the UES pre swallow $(\mathrm{mmHg})$. \\
\hline & $\begin{array}{l}\text { UES peak pressure } \\
\text { (UES PP) }\end{array}$ & $\begin{array}{l}\text { The peak pressure at the level of the UES measured immediately } \\
\text { post pharyngeal contraction }(\mathrm{mmHg}) \text {. }\end{array}$ \\
\hline $\begin{array}{c}\text { Proximal } \\
\text { esophageal } \\
\text { contractile measure }\end{array}$ & $\begin{array}{l}\text { Proximal esophageal } \\
\text { contractile integral } \\
(\mathrm{PCl})\end{array}$ & $\begin{array}{l}\text { An integral pressure measure of proximal esophageal contractility } \\
(\mathrm{mmHg} . \mathrm{cm} . \mathrm{s}) \text {. }\end{array}$ \\
\hline \multirow[t]{2}{*}{$\begin{array}{l}\text { Flow Timing } \\
\text { Variables }\end{array}$} & $\begin{array}{l}\text { Pharyngeal Distension- } \\
\text { Contraction Latency } \\
\text { (DCL) }\end{array}$ & $\begin{array}{l}\text { A timing measure from maximum pharyngeal distension to the } \\
\text { pharyngeal luminal occlusive contraction - a correlate of how well } \\
\text { the bolus is propelled ahead of the pharyngeal stripping wave, (in } \\
\text { milliseconds). }\end{array}$ \\
\hline & $\begin{array}{l}\text { Bolus Presence Time } \\
\text { (BPT) }\end{array}$ & The dwell time of the bolus in the pharynx (in milliseconds). \\
\hline $\begin{array}{l}\text { Global Swallow } \\
\text { Risk Index }\end{array}$ & $\begin{array}{l}\text { Swallow Risk } \\
\text { Index (SRI) }\end{array}$ & $\begin{array}{l}\text { A composite formula score designed to capitalize on the } \\
\text { directionality of aberrant swallow parameters. The original report } \\
\text { described SRI in patients with neuro-muscular disease and } \\
\text { aspiration on radiology (14). }\end{array}$ \\
\hline
\end{tabular}


Downloaded from journals.physiology.org/journal/ajpgi at KU Leuven Univ Lib (134.058.253.030) on November 10, 2020. 


\begin{tabular}{|c|c|c|}
\hline & $\begin{array}{c}\text { Group } 1 \\
(18-59 y r s)\end{array}$ & $\begin{array}{c}\text { Group } 2 \\
(60-80 y r s)\end{array}$ \\
\hline $\mathbf{N}$ & 36 & 14 \\
\hline Mean age (yrs) & $37(19-57)$ & $68(61-78)$ \\
\hline Gender & $13 \mathrm{~F}, 6 \mathrm{M}$ & $8 \mathrm{~F}, 9 \mathrm{M}$ \\
\hline Mean DAKKAK score & $0.19(0-3.5)$ & $0(0-0)$ \\
\hline Mean SSQ score & $45(0-169)$ & $24(0-67)$ \\
\hline \multicolumn{3}{|c|}{$\begin{array}{c}\text { Core Outcome Set Swallow Metrics (definitions in Table 1) } \\
\text { Grand Means (SD) }\end{array}$} \\
\hline $\mathrm{PhCl}$ (mmHg.cm.s) & $253(96)$ & $237(105)$ \\
\hline VCI (mmHg.cm.s) & $80(49)$ & $70(46)^{\#}$ \\
\hline MCI (mmHg.cm.s) & $107(45)$ & $103(64)$ \\
\hline HPCl (mmHg.cm.s) & $66(33)$ & $64(29)$ \\
\hline IBP $(\mathrm{mmHg})$ & $2.8(6.2)$ & $3.4(6.3)$ \\
\hline UES IRP $(\mathrm{mmHg})$ & $-3.6(4.8)$ & $-1.8(5.1)^{\#}$ \\
\hline UES RT (s) & $0.53(0.09)$ & $0.52(0.10)$ \\
\hline UES Max Ad (mS) & $5.25(1.22)$ & $5.06(1.14)$ \\
\hline \multicolumn{3}{|c|}{$\begin{array}{l}\text { Additional Swallow Gateway }{ }^{\text {TM }} \text { Specific Metrics (definitions in Table 1) } \\
\text { Grand Means (SD) }\end{array}$} \\
\hline UESCI (mmHg.cm.s) & $428(200)$ & $436(208)$ \\
\hline UES BP $(\mathrm{mmHg})$ & $64(32)$ & $68(45)$ \\
\hline UES PP $(\mathrm{mmHg})$ & $251(5)$ & $312(8)^{\#}$ \\
\hline PCl (mmHg.cm.s) & $285(9)$ & $286(12)$ \\
\hline DCL (s) & $0.47(0.09)$ & $0.46(0.09)$ \\
\hline BPT (s) & $0.62(0.16)$ & $0.61(0.17)$ \\
\hline SRI & $1.71(2.08)$ & $1.74(1.71)$ \\
\hline
\end{tabular}




\begin{tabular}{|c|c|c|c|c|c|c|}
\hline \multicolumn{7}{|c|}{ CORE OUTCOME SET METRICS } \\
\hline $\begin{array}{l}\text { Variable } \\
\text { Subtype }\end{array}$ & Variable & $\begin{array}{c}\text { GLMM } \\
\text { parameters }\end{array}$ & $\begin{array}{c}\text { Volume } \\
\text { Effect }\end{array}$ & $\begin{array}{l}\text { Viscosity } \\
\text { Effect }\end{array}$ & $\begin{array}{c}\text { Age } \\
\text { Effect }\end{array}$ & $\begin{array}{c}\text { Gender } \\
\text { Effect }\end{array}$ \\
\hline \multirow{4}{*}{$\begin{array}{l}\text { Pharyngeal lumen } \\
\text { occlusive pressure }\end{array}$} & $\begin{array}{c}\text { Pharyngeal contractile } \\
\text { integral } \\
\text { (PhCl) }\end{array}$ & $\begin{array}{l}F \\
P\end{array}$ & $\begin{array}{l}\uparrow 5.42 \\
0.001\end{array}$ & $\begin{array}{l}0.74 \\
\text { ns }\end{array}$ & $\begin{array}{c}2.01 \\
\text { ns }\end{array}$ & $\begin{array}{l}\uparrow 95.24 \\
<0.001\end{array}$ \\
\hline & $\begin{array}{c}\text { Velopharyngeal } \\
\text { contractile integral } \\
(\mathrm{VCl})^{*}\end{array}$ & $\begin{array}{l}F \\
P\end{array}$ & $\begin{array}{l}\uparrow 9.27 \\
<0.001\end{array}$ & $\begin{array}{c}0.07 \\
\mathrm{~ns}\end{array}$ & $\begin{array}{l}\downarrow 7.29 \\
0.007\end{array}$ & $\begin{array}{l}\uparrow 54.87 \\
<0.001\end{array}$ \\
\hline & $\begin{array}{c}\text { Mesopharyngeal } \\
\text { contractile integral } \\
(\mathrm{MCl})^{*}\end{array}$ & $\begin{array}{l}F \\
P\end{array}$ & $\begin{array}{c}0.46 \\
\text { ns }\end{array}$ & $\begin{array}{c}0.23 \\
\mathrm{~ns}\end{array}$ & $\begin{array}{l}\downarrow 8.98 \\
0.003\end{array}$ & $\begin{array}{l}\uparrow 181.2 \\
<0.001\end{array}$ \\
\hline & $\begin{array}{c}\text { Hypopharyngeal } \\
\text { contractile integral } \\
\text { (HPCl) }\end{array}$ & $\begin{array}{l}F \\
P\end{array}$ & $\begin{array}{l}\uparrow 2.87 \\
0.04\end{array}$ & $\begin{array}{c}1.53 \\
\mathrm{~ns}\end{array}$ & $\begin{array}{l}0.67 \\
\text { ns }\end{array}$ & $\begin{array}{l}1.29 \\
\mathrm{~ns}\end{array}$ \\
\hline $\begin{array}{c}\text { Hypopharyngeal } \\
\text { intrabolus } \\
\text { distension } \\
\text { pressure }\end{array}$ & $\begin{array}{l}\text { Hypopharyngeal } \\
\text { intrabolus distension } \\
\text { pressure } \\
\text { (IBP) }\end{array}$ & $\begin{array}{l}F \\
P\end{array}$ & $\begin{array}{l}\uparrow 26.30 \\
<0.001\end{array}$ & $\begin{array}{l}\uparrow 10.49 \\
<0.001\end{array}$ & $\begin{array}{l}\uparrow 3.36 \\
0.07\end{array}$ & $\begin{array}{l}\downarrow 12.06 \\
0.001\end{array}$ \\
\hline \multirow{3}{*}{$\begin{array}{c}\text { UES relaxation \& } \\
\text { opening }\end{array}$} & $\begin{array}{l}\text { UES integrated relaxation } \\
\text { pressure (UES IRP) }\end{array}$ & $\begin{array}{l}F \\
P\end{array}$ & $\begin{array}{l}\uparrow 43.47 \\
<0.001\end{array}$ & $\begin{array}{l}\uparrow 35.93 \\
<0.001\end{array}$ & $\begin{array}{l}\uparrow 21.71 \\
<0.001\end{array}$ & $\begin{array}{l}\uparrow 9.03 \\
0.003\end{array}$ \\
\hline & $\begin{array}{l}\text { UES relaxation time } \\
\left(\text { UES RT) }{ }^{*}\right.\end{array}$ & $\begin{array}{l}F \\
P\end{array}$ & $\begin{array}{l}\uparrow 32.87 \\
<0.001\end{array}$ & $\begin{array}{l}\downarrow \\
<0.25 \\
<0.001\end{array}$ & $\begin{array}{c}1.21 \\
\mathrm{~ns}\end{array}$ & $\begin{array}{l}\uparrow 43.49 \\
<0.001\end{array}$ \\
\hline & $\begin{array}{l}\text { UES maximum } \\
\text { admittance } \\
\text { (UES Max Ad) }\end{array}$ & $\begin{array}{l}F \\
P\end{array}$ & $\begin{array}{l}\uparrow 383.2 \\
<0.001\end{array}$ & $\begin{array}{l}\uparrow 51.84 \\
<0.001\end{array}$ & $\begin{array}{l}\downarrow 7.68 \\
0.006\end{array}$ & $\begin{array}{l}\downarrow 19.62 \\
<0.001\end{array}$ \\
\hline
\end{tabular}




\begin{tabular}{|c|c|c|c|c|c|c|}
\hline \multicolumn{7}{|c|}{ ADDITIONAL TO CORE OUTCOME SET SWALLOW GATEWAY ${ }^{\mathrm{TM}}$ SPECIFIC METRICS } \\
\hline $\begin{array}{l}\text { Variable } \\
\text { Subtype }\end{array}$ & Variable & $\begin{array}{c}\text { GLMM } \\
\text { parameters }\end{array}$ & $\begin{array}{c}\text { Volume } \\
\text { Effect }\end{array}$ & $\begin{array}{l}\text { Viscosity } \\
\text { Effect }\end{array}$ & $\begin{array}{c}\text { Age } \\
\text { Effect }\end{array}$ & $\begin{array}{l}\text { Gender } \\
\text { Effect }\end{array}$ \\
\hline \multirow{3}{*}{$\begin{array}{l}\text { UES contractile } \\
\text { measures }\end{array}$} & $\begin{array}{l}\text { Upper esophageal } \\
\text { sphincter contractile } \\
\text { integral (UESCI) }{ }^{*}\end{array}$ & $\begin{array}{l}F \\
P\end{array}$ & $\begin{array}{l}\uparrow 4.78 \\
0.003\end{array}$ & $\begin{array}{c}1.81 \\
\mathrm{~ns}\end{array}$ & $\begin{array}{c}1.05 \\
\mathrm{~ns}\end{array}$ & $\begin{array}{l}\uparrow 83.73 \\
<0.001\end{array}$ \\
\hline & $\begin{array}{l}\text { UES basal pressure } \\
\text { (UES BP) * }\end{array}$ & $\begin{array}{l}F \\
P\end{array}$ & $\begin{array}{c}0.33 \\
\mathrm{~ns}\end{array}$ & $\begin{array}{l}\downarrow 10.08 \\
<0.001\end{array}$ & $\begin{array}{c}0.32 \\
\text { ns }\end{array}$ & $\begin{array}{l}\uparrow 69.40 \\
<0.001\end{array}$ \\
\hline & $\begin{array}{c}\text { UES peak pressure } \\
\text { (UES PP) }\end{array}$ & $\begin{array}{l}F \\
P\end{array}$ & $\begin{array}{l}\uparrow 3.98 \\
0.008\end{array}$ & $\begin{array}{c}1.46 \\
\mathrm{~ns}\end{array}$ & $\begin{array}{l}\uparrow 38.13 \\
<0.001\end{array}$ & $\begin{array}{l}\uparrow 50.14 \\
<0.001\end{array}$ \\
\hline $\begin{array}{c}\text { Proximal } \\
\text { esophageal } \\
\text { contractile measure }\end{array}$ & $\begin{array}{c}\text { Proximal esophageal } \\
\text { contractile Integral (PCl) }\end{array}$ & $\begin{array}{l}F \\
P\end{array}$ & $\begin{array}{l}\uparrow 20.13 \\
<0.001\end{array}$ & $\begin{array}{c}\uparrow 7.88 \\
<0.001\end{array}$ & $\begin{array}{c}0.005 \\
\mathrm{~ns}\end{array}$ & $\begin{array}{l}\uparrow 20.22 \\
<0.001\end{array}$ \\
\hline \multirow[t]{2}{*}{$\begin{array}{l}\text { Flow Timing } \\
\text { measures }\end{array}$} & $\begin{array}{l}\text { Pharyngeal Distension- } \\
\text { Contraction Latency } \\
\text { (DCL) }\end{array}$ & $\begin{array}{l}F \\
P\end{array}$ & $\begin{array}{l}\uparrow 71.93 \\
<0.001\end{array}$ & $\begin{array}{l}\downarrow 14.09 \\
<0.001\end{array}$ & $\begin{array}{c}2.22 \\
\text { ns }\end{array}$ & $\begin{array}{l}\uparrow 5.35 \\
0.02\end{array}$ \\
\hline & $\begin{array}{c}\text { Bolus Presence Time } \\
\text { (BPT) }{ }^{*}\end{array}$ & $\begin{array}{l}F \\
P\end{array}$ & $\begin{array}{l}\uparrow 31.61 \\
<0.001\end{array}$ & $\begin{array}{c}\downarrow 8.59 \\
<0.001\end{array}$ & $\begin{array}{c}0.34 \\
\mathrm{~ns}\end{array}$ & $\begin{array}{l}\uparrow 14.00 \\
0.001\end{array}$ \\
\hline $\begin{array}{l}\text { Global Swallow } \\
\text { Risk Index }\end{array}$ & $\begin{array}{l}\text { Swallow Risk } \\
\text { Index (SRI) * }\end{array}$ & $\begin{array}{l}F \\
P\end{array}$ & $\begin{array}{l}\uparrow 31.71 \\
<0.001\end{array}$ & $\begin{array}{c}\uparrow 3.19 \\
0.04\end{array}$ & $\begin{array}{c}\uparrow 4.55 \\
0.03\end{array}$ & $\begin{array}{l}\downarrow 3.98 \\
0.05\end{array}$ \\
\hline
\end{tabular}




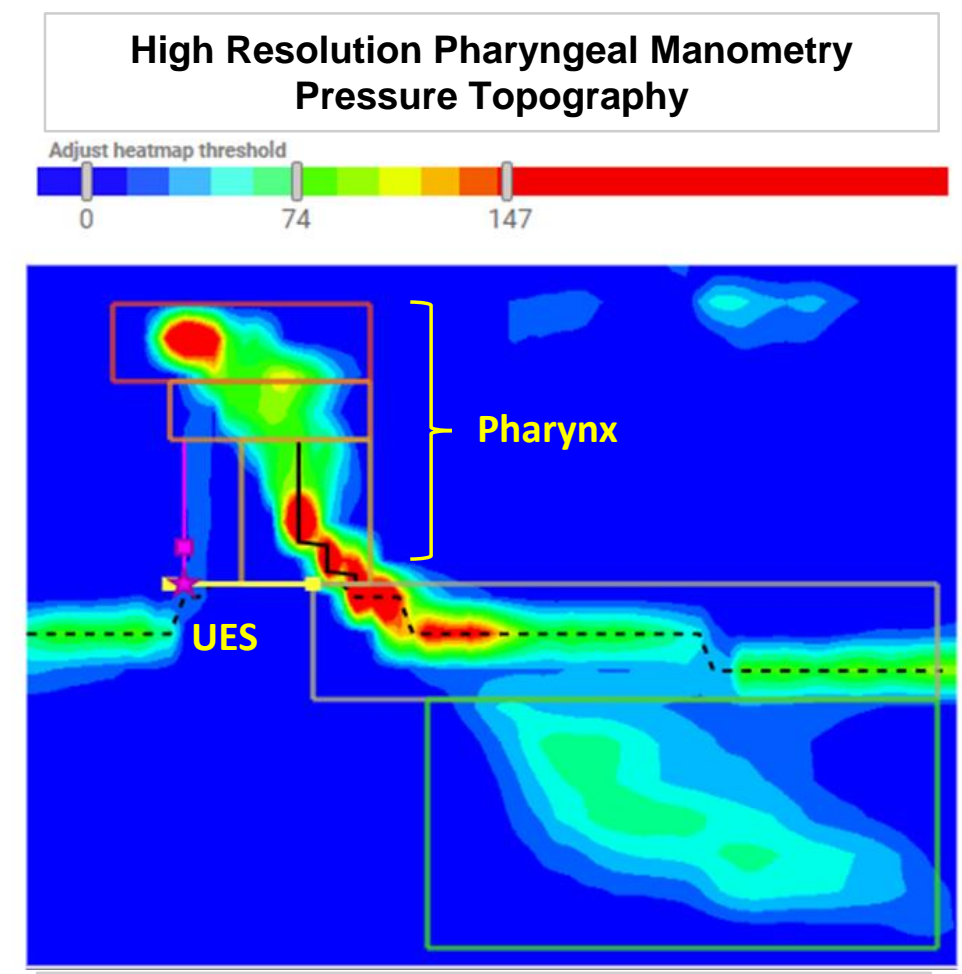

Pressure \& Impedance/Admittance Data Graphs
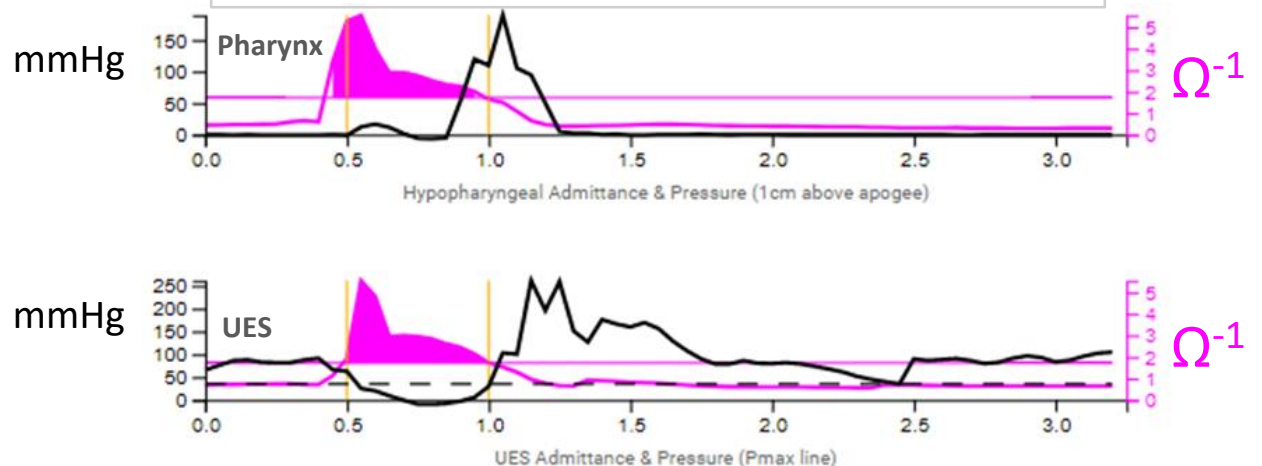